\title{
NARRATIVAS (AUTO)BIOGRÁFICAS SOBRE AS INFÂNCIAS E SEUS LUGARES NA FORMAÇÃO DOCENTE
}

\section{Silvania Regina Pellenz Irgang ${ }^{1}$}

\section{Valeska Fortes de Oliveira ${ }^{2}$}

\begin{abstract}
Resumo: Quando nos propomos a pesquisar a vida do professor, desenvolvemos uma escuta sensível de sua história, de seus saberes e os caminhos construídos no decorrer de sua formação docente. Foi por meio disto que desenvolvemos uma proposta de pesquisa-formação com três professoras de Educação Infantil, egressas do curso de Pedagogia, da Universidade Federal de Santa Maria (UFSM)/RS, com o intuito de nos aproximarmos de seus imaginários e narrativas (auto)biográficas sobre o lugar da infância na formação docente. Utilizamos uma pesquisa de abordagem qualitativa no processo de formação/autoformação que se baseia em referenciais teórico-metodológicos que viabilizam a discussão acerca da memória, história de vida e narrativas (auto)biográficas construídas em duas "experiências formadoras" intituladas "Baú de memória: lembranças da formação" e "Álbum de infâncias". Cada professora trouxe objetos pessoais guardados em seus "baús formativos" e narraram os sentidos e os significados em relação à infância na formação inicial e na experiência profissional, a partir de suas "recordações-referências". Na atualidade, os estudos sobre a infância transitam por diferentes áreas do conhecimento; conhecer o que os profissionais da Pedagogia compreendem sobre a infância é relevante para problematizar outras discussões no âmbito da educação. Assim, Christine Josso foi um dos aportes teóricos que nos permitiu vivenciar e repensar sobre as infâncias vividas, proporcionadas, (re)construídas com as crianças e nos debates em espaços acadêmicos e de formação. Isso fez com que pudéssemos refletir sobre o lugar que cada uma vem dando à infância em sua formação docente.
\end{abstract}

Palavras-chave: Narrativas (auto)biográficas. Infâncias. Formação docente.

\footnotetext{
1 Pedagoga, Especialista em Gestão Escolar, Mestre em Educação pela Universidade Federal de Santa Maria (UFSM)/RS. Professora de Estágio Curricular Supervisionado em Gestão Escolar pela Universidade Federal da Fronteira Sul (UFFS)/Campus Erechim/RS.

2 Pedagoga, Mestre em Educação pela Universidade Federal de Santa Maria (UFSM)/RS, Doutora em Educação pela Universidade Federal do Rio Grande do Sul (UFRGS)/RS, Pós-Doutora pela Faculdade de Ciências da Educação da Universidade de Buenos Aires/ Argentina. Professora Titular do Departamento de Fundamentos da Educação do Centro de Educação da UFSM.
} 


\section{NARRATIVA INICIAL}

Trabalhar com história de vida, memória e narrativas, oral e escrita, é um desafio ao pesquisador. A responsabilidade de interpretação e aproximação com os imaginários que constituem os saberes das professoras egressas do curso de Pedagogia na formação inicial e na experiência profissional sobre o lugar da infância na formação é um processo contínuo que permanece em cada uma de nós, no processo de conhecimento de si. Nesse artigo, apresentaremos parte da discussão realizada na pesquisa de Mestrado em Educação desenvolvida no Programa de Pós-Graduação em Educação da Universidade Federal de Santa Maria UFSM/RS, na linha de formação saberes e desenvolvimento profissional.

Para abarcar a dimensão que essa pesquisa teve em relação à infância e à formação docente, encontramos na pesquisa qualitativa a abordagem que sustenta os objetivos pensados e organizados na investigação-formação. Esta, possibilita adentrar por caminhos que sinalizam diversos sentidos, abrangendo além da objetividade, a subjetividade e o imaginário na pesquisa, no campo da educação e da formação de professores.

Nesse processo, propomos a três professoras de Educação Infantil, egressas do curso de Pedagogia da UFSM, o desafio de participarem da pesquisa-formação partindo de uma metodologia que envolve "experiências formadoras" (JOSSO, 2004), memória e história de vida. Aceito o convite, pedimos a elas que vasculhassem em seus baús de memórias, suas histórias, seus saberes e imaginários guardados, silenciados sobre a infância no decorrer de seus trajetos formativos.

A experiência formadora, segundo Josso (2004, p.39),

é uma aprendizagem que articula, hierarquicamente: saber-fazer e conhecimentos, funcionalidade e significação, técnicas e valores num espaço-tempo que oferece a cada um a oportunidade de uma presença para si e para a situação, por meio da mobilização de uma pluralidade de registros.

Neste processo, encontramos a possibilidade da formação/autoformação de professores como construção de si e (re)significação de saberes ao narrarem seus 
trajetos formativos, pois, segundo Josso (2004, p. 90),

cada narrativa traz um esclarecimento particular ao conceito de processo de formação. (...) Contudo, quando utilizamos no nosso trabalho de compreensão/interpretação alguns desses referenciais, é para compreendermos os processos de formação e não para verificar tal ou tal teoria das Ciências Humanas. (...) O vaivém entre estas narrativas provoca interrogações novas e faz progredir a compreensão do processo de formação.

Encontramos nas experiências formadoras um suporte de transformações (JOSSO, 2004) e (re)criação dos saberes e das significações imaginárias das professoras. Assim, duas vivências foram realizadas: "Baú de memórias: lembranças da formação" e "Álbum de infâncias". A partir delas, estabelecemos dois encontros formativos em que histórias singulares reconstruídas pela "memória coletiva” (HALBWACHS, 2006) foram relembradas, reinventadas no presente. Segundo o referido autor, "se o que vemos hoje toma lugar no quadro de referências de nossas lembranças antigas, inversamente essas lembranças se adaptam ao conjunto de nossas percepções do presente” (2006, p. 29).

Na primeira experiência formadora, "Baú de memória: lembranças da formação", as três professoras trouxeram objetos do tempo da formação inicial e narraram os sentidos e os significados atribuídos a eles no coletivo. Nesse dia, oportunizou-se o (re)encontro entre colegas, professora e aluna, profissionais de Educação Infantil dispostas a narrarem sobre si e os sentidos das histórias atribuídas a cada objeto na formação.

Na segunda experiência formadora, "Álbum de infâncias", as professoras egressas trouxeram imagens, fotografias e diferentes materiais que puderam (re)criar, através de um álbum de imagens, as representações de infâncias construídas na formação inicial e na experiência profissional em diferentes tempos, espaços e currículos de atuação e formação.

Cabe ressaltar, que, ao final de cada vivência, as professoras registravam, pela narrativa escrita, as representações vividas e o que destacavam de formativo na experiência. Esta dimensão do método biográfico busca compreender os sentidos, as significações dadas aos fatos, às práticas, aos desejos, aos sonhos, aos conhecimentos, às crenças e aos valores compartilhados nessas vivências. Afirma Thomson (1997, p. 57) que "ao narrar uma história, identificamos o que pensa- 
mos que éramos no passado, quem pensamos que somos e o que gostaríamos de ser". Ou seja, as histórias das professoras trazem aspectos significativos dos processos formativos do passado ao momento presente, procurando compreender as representações de si.

Buscamos a partir disso, conhecer as "ideias vivas" do cotidiano de suas docências. Segundo Marques (2004 p. 79),

\begin{abstract}
busca-se, hoje, uma educação diferente, centrada não em ideias congeladas e mortas para melhor se conservarem e transmitirem, mas em ideias vivas, brotando do chão da vida cotidiana dos alunos, da comunidade em que vivem, e alicerçada no saber de experiências de professor, pessoa humana participante dessa mesma vida e a ela atento sempre e renovadamente.
\end{abstract}

Evidencia-se, assim, que o professor é capaz de transformar suas ideias, a partir da reflexão e da aproximação com as crianças e suas infâncias. Esse processo criativo e vivo de estar na docência da educação infantil tem movimentado professores(as) para olhar a infância sobre diferentes ângulos, dialogando com diversas áreas.

Com esse intuito, esboçamos, a seguir, alguns entendimentos sobre esse diálogo entre a infância e a Pedagogia. Buscamos questionar "verdades" que, por vezes, estão distantes da criança com as quais nos deparamos na docência da Educação Infantil e que tem o direito de viver suas experiências de infância.

\title{
2 NARRATNAS DA INFÂNCIA
}

A infância é um tema que tem circulado nos diferentes campos de pesquisa e áreas de formação. A Pedagogia, por sua vez, é campo fértil para as discussões vivenciadas no cotidiano da Educação Infantil ao refletirmos sobre quem é a criança do século XXI e que infâncias temos oportunizado enquanto pedagogos(as) para que efetivamente seja uma escola da infância.

Desse modo, conhecer o lugar da infância na formação docente destas professoras foi a maneira que encontramos de nos aproximarmos do imaginário social instituído e instituinte daquelas que vivem o cotidiano com as crianças na Educação Infantil ou que tratam sobre elas em instituições de formação. Para 
isso, buscamos ouvir as professoras, suas histórias, seus saberes acerca da infância e os lugares revisitados pela memória das experiências das crianças que foram e das professoras que são. Encontros e desencontros marcados em suas histórias de vida, reconstruídos no ir e vir entre o passado, o presente e o futuro.

Nesse sentido, Kurek (2008, p.3) afirma:

percebo que não é ao tempo infantil que queremos retornar, nem a vida que tínhamos que queremos de volta, mas sim, queremos manter viva uma imagem potente que nos faz acreditar na possibilidade de um mundo diferente: a imagem de infância se faz necessária porque alimenta nossas utopias. A criança que fomos sofria com suas alergias e com medos do desconhecido. A criança que sonhamos nos devolve o devaneio sobre a eternidade.

A pesquisa buscou não ficar no "tempo infantil", como traz o autor, mas de revisitar as infâncias que viveram ao trazerem para o presente a possibilidade de apresentar outras infâncias para as crianças com as quais trabalham. Ou ainda, de instigar, na formação inicial, a discussão do que representa a infância no âmbito da Educação Infantil.

Segundo Arroyo (2008), “as verdades da pedagogia (...) verdades prévias que condicionam seu olhar e as ideias de infância que nos transmite" (2008, p. 119) estão sendo questionadas quanto ao protagonismo da infância e suas experiências. Ou seja, até quando essas "verdades" conservarão o pensar e o fazer pedagógico na infância?

Ampliar as discussões pelo viés de outras áreas do conhecimento sobre a infância pode ser o início de um diálogo interdisciplinar, fazendo com que a compreensão dessa pluralidade de infâncias seja significativa também no âmbito da formação de professores pelo olhar da antropologia, sociologia, psicologia, história e filosofia, por exemplo.

Segundo Arroyo (2008, p. 121),

a pedagogia retoma seu olhar sobre a infância na medida em que está sendo interrogada pelas ciências humanas e ambas estão sendo interrogadas pela própria infância. Nesse diálogo, outro pensar e fazer educativos são possíveis.

Esse é um diálogo urgente para que não fiquemos atrelados a uma visão romantizada e naturalizada da infância, nem tão pouco a uma visão reducionista a um tempo biológico ou etapa que toda e qualquer criança repete, frente à infini- 
dade de vozes que ecoam as infâncias. É a partir disso que surgem outras imagens sobre a infância, que perpassam por uma construção histórica e reconfiguram novos imaginários. Assim, "as ciências mostram que as imagens e verdades da infância com que a pedagogia se construiu também são construções históricas" (ARROYO, 2008, p. 121) e que precisam ser repensadas como um saber dinâmico em (des)construção.

No âmbito da sociologia da infância, Sarmento (2008) olha para a infância como uma categoria social do tipo geracional, em que a criança vem se produzindo e sendo produzida como ator social de sua própria história, da sua cultura e de seus saberes. Em vista disso, as discussões no campo da Pedagogia, quando encontra espaço para esse diálogo, trazem diferentes construções acerca da infância, dependendo do contexto social, cultural, histórico, político e econômico que os sujeitos estão inseridos.

Para Sarmento (2005, p. 366),

\begin{abstract}
A geração da infância está, por consequência, num processo contínuo de mudança, não apenas pela entrada e saída dos seus actores concretos, mas por efeito conjugado das acções internas e externas dos factores que a constroem e das dimensões de que se compõe.
\end{abstract}

Por estar em permanente processo de mudança, a "geração da infância" precisa fazer parte das discussões na Pedagogia, para que possamos nos aproximar das crianças como sujeitos produtores de cultura, saberes, valores e identidades. Se a infância é algo que nos marca, certamente para as crianças com as quais trabalhamos ou pesquisamos também há esse pertencimento do vivido. Resta saber, que marcas andamos produzindo nessas crianças.

Cabe ainda ressaltar que, a infância não é inerente às crianças e, segundo Sarmento (2005), estas devem ser olhadas como atores sociais concretos que em cada momento histórico, social, cultural, econômico integram a categoria geracional da infância. Miguel Arroyo é mais enfático e diz que "pouco sabemos dos sujeitos reais que a vivem" (2008, p. 124). Realmente, a Pedagogia ainda vê a criança como produto de processos pedagógicos, didáticos e administrativos. Se reconhecemos a criança como "um corpo de verdade construído ao longo da história" (ARROYO, 2008, p. 125) por que a ignoramos ou a idealizamos como estivesse fora desse lugar? 
Na perspectiva de Kuhlmann Jr (2001, p. 31),

\begin{abstract}
é preciso considerar a infância como uma condição da criança. $\mathrm{O}$ conjunto das experiências vividas por elas em diferentes lugares históricos, geográficos e sociais é muito mais do que uma representação sobre essa fase da vida. É preciso conhecer as representações de infância e considerar as crianças concretas, localizá-las nas relações sociais, etc, reconhecê-las como produtoras da história.
\end{abstract}

Por isso, conhecer as infâncias e discuti-las, na Pedagogia, é uma das possibilidades de analisar se o encontro entre criança e infância tem acontecido nos processos formativos. Segundo as autoras Oliveira; Oliveira (2005), este encontro nem sempre acontece, pois ser criança não lhe dá a garantia de ter infância.

Nessa breve narrativa sobre alguns entendimentos sobre a infância, deixamos a proposta de reflexão, diálogo e questionamento, tanto na Pedagogia, nas políticas, quanto na docência, nos currículos, na organização escolar, sobre as experiências de infâncias propiciadas às crianças. Para isso, é importante escutar as crianças, interrogá-las a respeito de si e os sentidos que atribuem ao vivido, para que ela não seja apenas a projeção de um adulto.

Cabe ressaltar ainda, que os estudos sobre a infância reconhecem as diferenças e as desigualdades nas formas de vivê-la. Portanto, não falamos somente em uma única infância, é importante referirmos a "infâncias" (ARROYO, 2008) e às diversidades que a constituem.

Encontramos, assim, a partir das narrativas, oral e escrita, das professoras Girassol, Rosa e Violeta, a possibilidade de refletir sobre a relação entre formação e infância. O processo de rememoração acerca dos saberes e dos imaginários na formação permitiram (re)significações também em relação aos lugares da infância. Estes foram decorrentes de experiências do passado e da reflexão da prática atual, o que possibilitou outros olhares sobre a infância e a criança, nos diferentes espaços formativos. 


\section{NARRATMAS FORMATIAS DE SI}

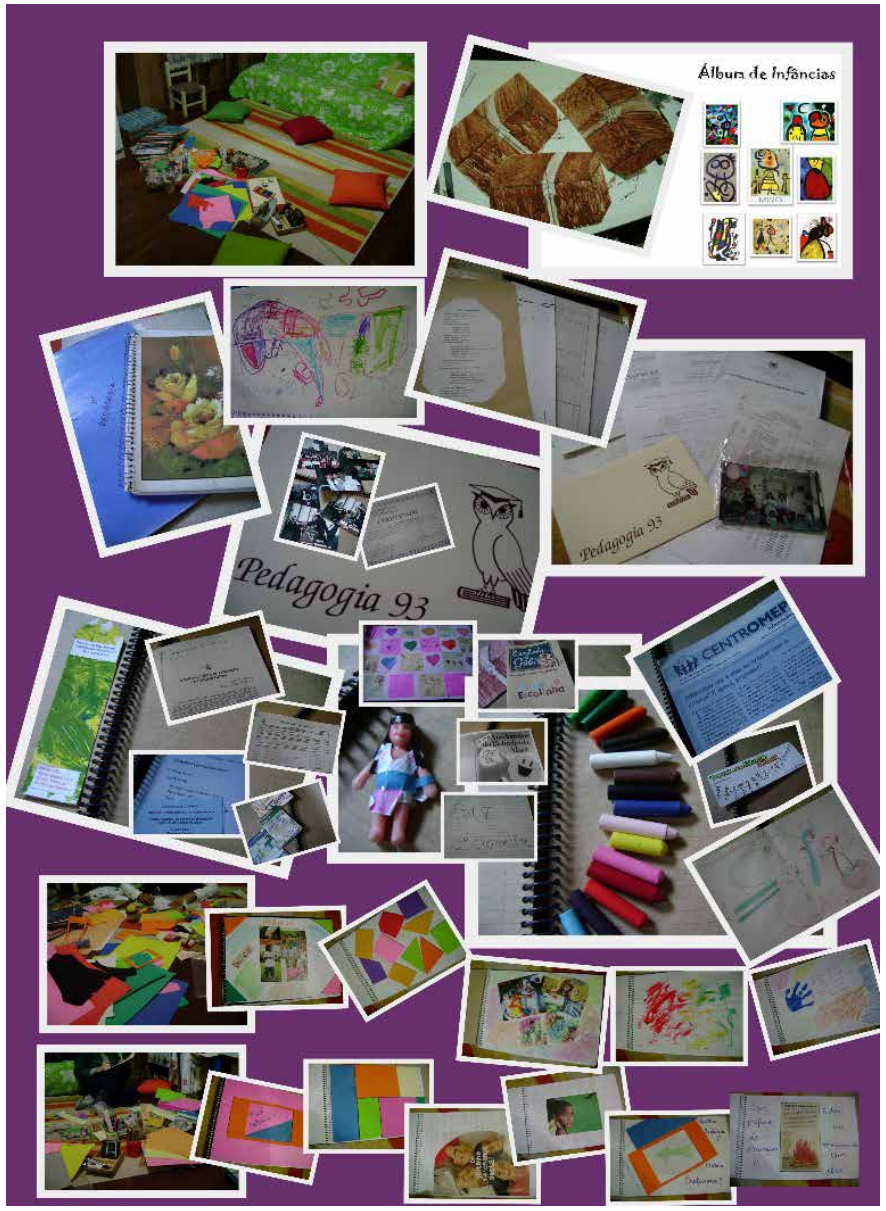

Fonte: Arquivo pessoal das autoras 
Iniciamos com a coletânea de imagens do antes, durante e depois das experiências formadoras. A importância que essa simbologia tem na organização do espaço; os convites para participação das "experiências formadoras"; os objetos trazidos por elas, como cadernos, convites de formatura, fotografias, marcadores de livros; desenhos das crianças; boneca; textos; e as produções dos álbuns de infâncias que finalizaram as experiências com a escrita autobiográfica do vivido. As imagens falam por si só, mas as narrativas contam as histórias, dão sentido e significado para o vivido por cada uma delas e a todas ao mesmo tempo.

Na primeira vivência, o convite foi confeccionado em formato de baú, em que ao abri-lo, as professoras tinham uma carta-convite, mencionando o objetivo da pesquisa; a existência do Termo de Consentimento Livre Esclarecido e do Termo de Confidencialidade e a possibilidade de aceitarem esse convite de participação da pesquisa. Solicitamos, também, que trouxessem algumas recordações do tempo da graduação em Pedagogia, vivido por cada uma, como fotografias, históricos escolares, cadernos, agendas, bilhetes, entre outras "recordações-referências", que "são simbólicas do que o autor compreende como elementos constitutivos da sua formação" (JOSSO, 2004, p. 40).

Para melhor elucidar o termo "recordações-referências" trago o entendimento da referida autora, a fim de qualificá-las como experiência formadora, pois significam o que foi aprendido, refletido, bem como são formas diferentes das professoras falarem de si, de suas identidades e de suas subjetividades. Ou, ainda, a recordação-referência "significa, ao mesmo tempo, uma dimensão concreta ou visível, que apela para as nossas percepções ou para as imagens sociais, e uma dimensão invisível, que apela para emoções, sentimentos, sentido ou valores" (JOSSO, 2004, p. 40).

Foi a partir dos sentidos e significados de objetos que as professoras selecionaram em seus baús de formação que iniciou o trabalho de memória individual, mas também coletiva, pois ao narrarem os significados das lembranças reviveram um processo formativo que trouxe à tona uma pluralidade de significados pessoais e profissionais sobre as questões da infância na formação docente.

Nesse sentido, Von Simson (1997, p.67) aponta para o fato da memória ser ao mesmo tempo

subjetiva ou individual (porque se refere a experiências únicas vivenciadas pelo indivíduo), mas também social porque é coletiva, pois se baseia na cultura de um agrupamento social e em códigos que são aprendidos nos processos de socialização que se dão no âmago da sociedade. 
Com isso, não pretendemos ficar engessadas às lembranças produzidas nas representações de infâncias das professoras, mas a partir destas foi possível refletir, reviver e partilhar aprendizagens singulares que se construíram a partir de seus saberes e suas vivências na formação docente.

Destacamos a importância da fotografia nesse processo de rememoração. Duas professoras trouxeram fotos como objetos-referências e para a vivência elas foram mais que imagens, elas contaram histórias. De acordo com Oliveira (2010, p.75),

Através das histórias de vida contadas oralmente e pelo recurso da fotografia, nos aproximamos de imagens reconstruídas no presente a partir dos significados atribuídos aos trajetos vividos. Conhecemos os processos de formação, visitamos as paisagens, os comportamentos, os tempos vividos através dos sentidos trazidos ao momento de fala. Falar de si, falar a partir dos outros, como uma intenção proposta por um investigador, de pesquisar em si, auxiliado por imagens fotográficas, transporta-nos a outros tempos, a outros espaços e a outras práticas discursivas significativas, permitindo compreendermos o deslocamento de sentidos individual e coletivamente na sociedade.

Optamos por fazer recortes das narrativas orais vividas na experiência formadora pelas professoras Girassol (G), Rosa (R), Violeta (V), de modo que uma intervinha na narrativa da outra a cada história contada, relembrada, o que propiciou o movimento reflexivo entre elas, suas aprendizagens e suas memórias.

(R) Eu procurei o curso de Pedagogia foi para isso, foi para estudar algo que eu já conhecia, porque eu já trabalhava. (...)peguei meu caderno, um caderno que tem as duas disciplinas de metodologia do pré-escolar, que é mais próximo da Educação Infantil.(...) comecei a ler, a ver as possibilidades, possibilidades que eu também não via. $(\mathrm{G})$ eu trouxe também um material desses, as contribuições que me marcou muito durante o curso. Aqui fala do Piaget, dos estágios que até hoje, não tem como tu fugires(...). Esse aqui foi o nosso estágio (...) A gente também teve a oportunidade de ficar frente à prática, à realidade com as crianças. (...) eu trouxe uma fotos da formatura. Foi uma vitória para mim. (...) Aqui também gurias, me deu uma saudade muito grande. Mas ao mesmo tempo fiquei tranquila, agora com toda caminhada que eu já tenho que lá já no meu estágio eu já fazia a diferença com essa turma de Pré-Escola.(...) Eu fiz o concurso, era a coisa que eu mais sonhava, era ser chamada no concurso e eu ainda consegui para ti ver, para mim 
foi uma vitória também. (V) eu fui procurar nas minhas coisas, ver o que ia me ajudar e aí achei esse texto.(...) como é a organização do trabalho pedagógico na Educação Infantil.(...) gostei bastante de trabalhar com crianças pequenininhas. E esse texto aqui, para mim foi e tem grande significado. (R)existe uma formação que é para ser com o trabalho com a criança, mas é que os professores dão para os alunos aquilo que eles acham que o aluno tem que ler e não, necessariamente, $o$ que depois vai lhe ser útil no trabalho com crianças pequenas(...)Porque senão quando vê parece que tu ficas discutindo no vazio, falando no vazio e olhando os outros e tu não sabe muito bem como tu vais fazer isso.(...) eu acho que tem coisas que nunca vai estar bom, porque a gente sempre vai querer uma coisa melhor, porque as crianças vão mudar, porque a vida da gente vai mudar. (V) eu gosto de brincar, é por ai que eu acho que eu me comunico com as crianças, gostar de brincar e esse texto aqui diz, ousar a brincar realmente assim com a criança porque é assim que a gente vai tocar elas. (...) trouxe desenhos dos meus alunos. (...) achei essa bonequinha que eu fiz um trabalho em Artes. (...) encontrei um marca livro feito com tinta. (R.) Pois é, eu vejo o quanto eu conseguia olhar o que eu já tinha feito com outro olhar. Acho que tu também, porque hoje tu tens outro olhar, tu olhas as coisas que tu fez e faz, é diferente de quando tu estudavas para ser professora.(...) essa identificação que a gente tem com a criança, não é porque achar de que gosta de criança, não é isso, mas isso é construído. Não é simplesmente eu gosto de criança e vou lá e vou trabalhar direitinho. É porque tu tens conhecimento sobre isso. (V) eu acho que a gente tem que ouvir a criança mais um pouco (...) fazer uma relação de aprendizagem realmente com aquilo ali, com a criança e aí é que está a diferença em ouvir, observar. (G) esses primeiros contatos, esses primeiros meses, como é importante, como marca essa relação, essa transição da saída de casa para a escola, é complicada. (...) Mas é com as brincadeiras que tu vais motivar eles para que eles sintam vontade de estar na escola. (R) É, não tem receita. Eu acho que é estar perto da criança, estar ali. (V) é na prática que tu vais revendo algumas coisas. $(\mathrm{G})$ É, e aí é que tu vais enriquecendo tua prática, tuas aprendizagens. (R) Isso, vai tentando, experimentando, acho que é por aí. Tu não sai cru, mas também tu não sai com todo esse traquejo. Daí tem que ir vendo, vivendo. (V) criatividade eu acho que tem que ter bastante e desenvolver na criança também, instigá-la. E esse trabalho eu me lembro um pouco da minha infância.

Como podemos observar nas narrativas das professoras $(G),(R)$ e $(V)$, os objetos trazidos são repletos de significados que ao narrarem uma para as outras, diversos sentidos foram se estabelecendo e a reflexão sobre o/a professor/a de Educação Infantil e seu trabalho junto à criança tem um papel relevante na construção das infâncias. Elas buscaram nos saberes construídos na Pedagogia embasamento teórico-didático-metodológico para trabalharem com as crianças e 
isto reflete os saberes construídos sobre a infância na formação, pois estes foram revisitados, (re)construídos no diálogo da experiência formadora, bem como nas relações feitas com os saberes da experiência.

Quando as professoras mencionam a importância de ouvir a criança, de olhá-la de perto, de levar em consideração as necessidades e suas manifestações, encontro nesse diálogo questões pertinentes aos estudos e as discussões recentes sobre a infância. É por esse caminho que a infância vem questionar a Pedagogia e desafiar o/a professor/a a desenvolver esse olhar sensível no cotidiano da prática docente. Tarefa complexa, mas necessária, pois é por meio deste olhar que o/a professor/a pode se aproximar dos imaginários das crianças, de seus saberes, dando-lhes aporte cognitivo e afetivo na construção de suas identidades. Segundo Ferreira; Eizirik (1994, p.6),

a criança, ao chegar à escola, não abandona o mapa intelectual a que até então recorreu para orientar-se no mundo, para resolver suas questões. Nesse mapa estão presentes referentes da sua identidade: mitos, crenças, idéias próprias de seu grupo social, de que ela não pode se desfazer. Embora não seja um adulto em miniatura, ela carrega consigo uma subjetividade de alguma forma instituída a partir de uma cultura. Nessa criança estão presentes fantasias, desejos, expectativas, inclusive em relação à escola. O desafio que nos é dado passa pela compreensão desse dentro/fora do aluno - e, por que não dizer, do professor - que chega na escola, que sai, que não quer entrar ou que é expulso dela.

As relações estabelecidas pelas autoras movimenta as subjetividades de cada um, de modo que a observação e a escuta sensível nos oferecem suportes de compreender essa cultura do lado de dentro/fora. Realmente, é um desafio desvendar esse "mapa", mas, mais do que nunca, é necessário, para que possamos afirmar nosso compromisso com a educação das crianças e suas infâncias.

As narrativas trazidas pelas professoras, nesse momento, demonstram o quanto estão envolvidas em questões que propiciam espaços para a construção de infâncias com as crianças. Conhecer o lugar que se tem pensado e oferecido para a infância é importante para avançarmos nas discussões que envolvem a criança no âmbito escolar. Pode ser, que este lugar, muitas vezes, é idealizado, mas nem sempre concretizado.

Por isso, despertar questionamentos sobre temas que permeiam a construção da infância em diferentes espaços faz com que se amplie as possibilidades do encontro entre criança e infância. Um encontro que possa ter significados, 
brincadeiras, criatividade, afetividade, enfim, uma formação que professores reflexivos desenvolvam, a fim de que possam contribuir com a construção de um lugar de destaque para a infância.

As professoras procuram dentro de si o lugar que elas atribuem à infância em seus trajetos de formação e com isso, na narrativa de uma e de outra, rememoraram a pluralidade de sentidos atribuídos às infâncias encontradas, escondidas, (re)construídas pelo trabalho com a memória. Elas ainda vão além, buscam em seus baús os imaginários instituídos sobre a infância e tentam produzir pelo vivido, imaginários instituintes nos espaços de atuação profissional.

Nesta perspectiva, podemos inferir que os saberes docentes (TARDIF, 2002) são construídos pelos professores ao longo de suas trajetórias, nos diversos espaços e tempos pessoais e profissionais. É por meio dos saberes pessoais, profissionais, experienciais, curriculares e disciplinares que nós, professores e alunos, acionamos na memória as vivências e as marcas que nos produziram e produzem como profissionais da educação.

De acordo com Tardif (2002, p. 36), o saber docente é “(...) como um saber plural, formado pelo amálgama, mais ou menos coerente, de saberes oriundos da formação profissional e de saberes disciplinares, curriculares e experienciais". Nesse sentido, os saberes profissionais são oriundos dos processos formativos e das experiências vividas pelos professores na sua pluralidade e heterogeneidade.

Também, observamos que as vivências em disciplinas curriculares, quando acadêmicas do curso de Pedagogia, possibilitaram-nas desenvolver ludicamente o trabalho com a criança na faixa etária da Educação Infantil. Além disso, problematizaram as dificuldades frente as demandas das discussões sobre as infâncias de crianças bem pequenas no curso de Pedagogia.

Mais do que lembranças de formação, lembranças de vida, de subjetividades foram revividas, de modo que as significações destes momentos demonstram a dimensão pessoal e profissional que constituí o ser professor (NÓVOA, 1992). Seguem as contribuições de Oliveira (2004, p. 17) sobre a importância do trabalho com a história de vida na pesquisa ao dizer que as "histórias de vida põem em evidência o modo como cada pessoa mobiliza os seus conhecimentos, os seus valores, as suas energias, os seus repertórios". Quando cada professora iniciou a contar sua própria história, o que a referida autora mencionou ficou evidente e as narrativas desvelaram, nesse instante, aquilo que era de mais precioso para elas. No entanto, as narrativas não eram individuais somente, elas se complementavam e produziam reflexões verbalizadas pelas professoras em relação às teorias; 
às práticas de Educação Infantil; o brincar e ser sujeito de mudança e construção.

Os objetos trazidos tinham histórias vivas que foram sendo reconstruídas no decorrer da vivência e que ao final registraram pela narrativa biográfica as impressões e os significados dessa experiência:

Vejo que me aproximo pouco do que foi minha formação inicial, talvez porque esteja tentando ser diferente, fazer diferente, ver diferente... Meus referenciais sobre a infância são, na maioria posteriores, só falava do que vivo hoje, pelo menos com mais propriedade. Acho que também falta maturidade quando se é aluno para poder ver o que é importante na educação da criança... Estar aqui e rever este processo me coloca também de frente para o que preciso fazer no meu trabalho no curso de Pedagogia, é uma maneira de refazer a história, minha e de outras pessoas. (Professora Rosa)

\begin{abstract}
A busca pelos objetos me fizeram relembrar coisas da minha infância, coisas da minha formação importantes e que, hoje, fazem a diferença no meu trabalho (ano passado no berçário I, da Escola Imaginare) e, futuramente, no meu trabalho na escola. Na conversa de hoje muitas coisas vem à tona: sentimentos, emoções que me re-significam, me fazem repensar atitudes e valores, me fazem perceber minha formação e minha trajetória na universidade e o quanto amadureci e aprendi. Trajetória e fatos que conto e que mexem comigo ao contar, pois são esses acontecimentos e fatos que me constituem o que sou hoje e que ao lembrar me re-significam. Hoje, 06/04, que momentos bons, agradáveis de cheiros, gostos e sensações. Momentos que nos tocam. (Professora Violeta)
\end{abstract}

Foi emocionante resgatar a minha formação e mais ainda as disciplinas que me aproximaram da prática. E, após anos de prática, pude perceber se queremos avançar no processo educacional é preciso mudar nossas ações, seja na forma de lidar com o outro, no interesse pela aprendizagem, ou seja, na forma de avaliar conhecimentos. Gostaria de deixar registrado a minha satisfação em rever objetos que fizeram parte de minha trajetória no curso de Pedagogia como: fotos, certificados, convite, histórico, trabalhos, que todos os esforços não foram em vão, hoje, me sinto realizada profissionalmente e faço o que mais gosto. É estar próxima das crianças acompanhando os progressos e avanços e contribuindo com as aprendizagens significativas. (Professora Girassol)

Com essa vivência foi possível repensar o papel da formação inicial e da experiência profissional como dispositivo de formação/autoformação individual e coletiva. Segundo Josso (2006, p. 379), “o processo é pôr-se a caminho, nes- 
sa busca de compreensão de si, de componentes de nossa história, de tomadas de consciência do que nos move, nos interessa, nos guia, nos atrai." Com isso, outros desafios, outros caminhos e oportunidades são possíveis, num contínuo aprender.

Quando as professoras referem-se as suas próprias infâncias, novas significações são instituídas, no tempo presente, radicado pelo viés do imaginário. Conforme Oliveira (2006, p.184),

as histórias da nossa infância e da nossa escolarização são revisitadas no sentido das referências construídas: temos recursos experienciais e também representações sobre escolhas, influências, modelos, formação de gostos e estilos, o que é significativo para a reflexão sobre o que somos hoje e para as possibilidades autopoiéticas que nos singularizam como pessoas e professores.

Assim, as aprendizagens situadas em tempos e espaços determinados e precisos atravessam a vida dos sujeitos. $\mathrm{O}$ acesso ao modo como cada pessoa se forma, como a sua subjetividade é produzida permite-nos conhecer singularidades da sua história, como age, reage e interage com os seus contextos. A própria narrativa sobre a trajetória profissional pode auxiliar na tematização da atuação presente do professor, construindo um arquivo de memória das vidas de professores.

Nesse sentido, a vivência mobilizou as reflexões do vivido, acionando no campo simbólico as significações imaginárias sobre si mesmas, a infância e a formação docente. Essa rememoração dos objetos significativos no trajeto formativo mobilizou a (re)significação dos imaginários instituídos na formação docente, bem como propiciou uma reorientação na forma de pensar entendida por Josso (2006) como "momento charneira".

De acordo com a referida autora (2006, p.378), quando se trabalha numa perspectiva biográfica, é o momento de "reconstrução de quem faz história no percurso de vida relatado", ou seja,

é o momento em que se trata de compreender como essa história articula-se como um processo - o processo de formação - que pode ser depreendido mediante as lições das lembranças que articulam o presente ao passado e ao futuro. (...) Nessa fase do trabalho biográfico centrado na compreensão e na interpretação dos relatos com olhares cruzados, novos tipos de laços aparecerão.

Portanto, a experiência formativa, "Baú de memória: lembranças de formação", proporcionou um processo de aprendizagens profissionais e pessoais às 
professoras egressas do curso de Pedagogia da UFSM. Pois, ao relatarem seus trajetos formativos; partilharam acontecimentos, fatos, modelos, marcas, emoções e valores formativos a partir das suas narrativas. Concluíram, também, que o processo de mudança, de criação é um desafio constante na formação/autoformação docente.

Corroboramos com Pimenta (2005, p. 29) quando diz que o professor está num contínuo processo de formação/autoformação que propicia a (re)significação de seus saberes:

(...) pensar sua formação significa pensá-la como um continum de formação inicial e contínua. Entende, também, que a formação é, na verdade, autoformação, uma vez que os professores reelaboram os saberes iniciais em confronto com suas experiências práticas, cotidianamente vivenciadas nos contextos escolares. É nesse confronto e num processo coletivo de troca de experiências e práticas que os professores vão constituindo seus saberes como praticum, ou seja, aquele que constantemente reflete na e sobre a prática.

A partir disso, a vivência propiciou contribuir com formação/autoformação das professoras, que puderam reconhecer e valorizar os saberes experienciais construídos por elas no trabalho docente e repensarem sobre o lugar da infância em seus trajetos formativos.

Na segunda experiência formadora, "Álbum de infâncias”, foi solicitado que as professoras trouxessem imagens, fotografias e diferentes materiais que pudessem (re)criar, através de um álbum de imagens, as representações de infâncias construídas na formação inicial e na experiência profissional em diferentes tempos, espaços e currículos de atuação e formação.

Os saberes docentes e as significações imaginárias sobre a infância antes, durante e depois da formação inicial no curso de Pedagogia na UFSM foram representados nos álbuns de infâncias por imagens, fotografias, texturas, cores, palavras, sentidos e significados de experiências formativas construídas pelas professoras Rosa e Violeta, pois na ocasião, a professora Girassol não pode estar presente. Segundo Alcântara (2001, p. 88), "as imagens são detonadoras de emoções. Têm o poder de despertar a memória das experiências acumuladas dentro de nós trazendo à tona registros de lugares e tempos já vistos e vividos".

Ao propor essa experiência formadora com a construção de imagens de infâncias, pensamos em acionar a memória das professoras e suas significações imaginárias de tempos formativos, pois estas "buscam lançar um outro olhar para compreender os sentidos atribuídos pelos sujeitos aos fatos, pessoas, situ- 
ações e também ao que estes acionam nele" (DAL-FORNO, 2005, p. 52). Com isso, uma outra forma de pensar constituiu as narrativas das professoras quando os sentidos instituídos, em diferentes tempos-espaços de formação, possibilitaram, no presente, novas significações à criança e à infância. Segundo as contribuições de Castoriadis (1987, p. 231),

para além das definições puramente anatômicas ou biológicas, homem, mulher e criança são o que são mediante as significações imaginárias sociais que os fazem ser assim. (...) Denomino imaginárias essas significações porque elas não correspondem a - e não se esgotam em - referências a elementos "racionais" ou "reais", e porque são introduzidas por uma criação. E denomino sociais, pois elas somente existem enquanto são instituídas e compartilhadas por um coletivo impessoal e anônimo.

Nesse sentido, as professoras representaram por meio de imagens e colagens as vivências com as crianças, as possibilidades de (re)significação de saberes, marcas subjetivadas com as crianças, como professoras de Educação Infantil, possibilitando a (re)construção de infâncias que transformaram suas maneiras de pensar e estar na profissão docente.

As significações das professoras Rosa e Violeta passeiam por lugares sociais e históricos da infância, em um movimento de idas e vindas entre o mundo infantil e adulto. O contexto trazido pelas professoras institui "um magma de significações imaginárias sociais, que podemos e devemos denominar mundo de significações" (CASTORIADIS, 1982, p. 404) que as constituem e são referenciais de atuação profissional.

As significações construídas sobre a infância tanto no curso de Pedagogia, quanto nas experiências profissionais, instauram imaginários instituídos do brincar, de experimentar, de vivenciar e de compor repertórios de diversas maneiras do ser professora e, assim, compreender as diferentes infâncias. De acordo com Redin (2008, p.11), é preciso ter um olhar sensível para a questão da criança e sua infância na escola de Educação Infantil, pois

as crianças estão sendo privadas de sua curiosidade, de sua imaginação, da liberdade de movimentos; estão empobrecendo suas culturas lúdicas, que estão sendo engolidas pela cultura de massa. A escolarização da infância ao invés de reconhecer e potencializar as linguagens infantis tenta homogeneizar suas práticas e concepções. A multiplicidade de experiências, a riqueza da diversidade, o inusitado do cotidiano, acabam se achatando numa mesmice sem sabor de saber.

A professora Rosa, que já havia tido experiência profissional com crianças 
na Educação Infantil antes de ingressar no curso de Pedagogia, questionava o que era válido na experiência e conclui que "ser criança era estar em movimento!". Ela representou sua reflexão pela imagem do olhar de um menino, remetendo-se também a importância do olhar da/para a criança. No curso de Pedagogia quis experimentar-se e conhecer que outras professoras ela poderia ser, para isso colou sua fotografia vestida de clown.

O curso de pedagogia...esse aqui é o curso de clown que eu fiz, aí eu coloquei. "Experimentações", porque eu vejo que eu fui experimentando outras coisas. Como é que eu queria ser professora então? Já que eu queria ser. Era outra infância que eu estava vendo? Outra professora? (Professora Rosa)

A construção de saberes a partir das próprias experiências, anteriores e durante o curso de Pedagogia oportunizou a professora Rosa o reconhecimento e a reelaboração do imaginário sobre formação/autoformação quando continua sua fala ao diz que "no curso eu percebi o quanto eu necessitava de formação". A partir desta reflexão, percebemos a dimensão da pesquisa-formação, na qual "os participantes vão entrar figurando como atores-pesquisadores em busca de conhecimento e como atores-aprendentes responsáveis pelo saber-fazer e pelo saber-pensar" (JOSSO, 2004, p. 147, grifos do autor).

Para a professora Violeta, os saberes da infância, na universidade, foram marcados pela socialização entre as crianças, entre adultos e crianças e a criança e seu meio. Isso é possível quando o professor se disponibiliza a construir imagens diversas sobre a infância, oportunizando à criança momentos lúdicos do brincar e do experimentar. No curso de Pedagogia, a professora Violeta foi dando um lugar de socialização à infância e pela dimensão simbólica do colorido, as diversas formas de (re)encontrá-la.

\footnotetext{
Aqui eu coloco infância construída na universidade a questão da socialização, do colorido, das formas diversas (...). Infância é lambuzar-se. O conceito de infância construído na universidade, momento da criança brincar e nós como professoras, possibilitar aos nossos alunos a vivenciar a infância. (Professora Violeta)
}

A professora Violeta representou sua fala por recortes de revista, de crianças brincando, pintando, pulando corda, conversando e coloriu com cores diversas 
os espaços em branco da folha. Depois, cortou pedaços irregulares de papel colorido, em diferentes cores, simbolizando as crianças e as infâncias. "Infância colorida, cada criança como um retalho desses papeis coloridos, cada um com sua forma, com suas vivências, mas o colorido representa a vontade de experimentar e viver que a criança tem" $(V)$.

Em relação ao colorido, a professora Rosa também representa por papeis coloridos uma das páginas do álbum, dizendo que: "eu coloquei esse colorido, porque para mim sempre foi isso trabalhar com a criança, acho que até, às vezes, meio idealizado, meio romântico" (Rosa). Esta fala de Rosa suscita-nos a reflexão sobre o imaginário instituído da infância idealizada, romantizada que ainda simboliza o discurso de muitas professoras e acadêmicas ao serem indagadas sobre a infância.

No entanto, problematizar esse imaginário na formação inicial é importante, para que possamos ampliar a discussão sobre a infância e tudo que a constitui nos contextos sociais, culturais e históricos de cada lugar. Ao mesmo tempo, esse colorido é indispensável, pois precisamos nos encantar mais com os processos vivenciados na infância. Como professoras, dar cor, cheiro, sabor e sentido para esses momentos faz com que a infância tenha outros registros na memória das crianças, que quando adultos lhe garantem lembranças e memórias formativas.

Quando a professora Violeta traz as significações de infâncias coloridas, de experimentação, de movimento, de lambuzar-se com crianças de zero a três anos traz à tona a discussão da infância também com a criança bem pequena que ainda precisa ser consolidada no curso de Pedagogia. No entanto, foi na experiência profissional que ela construiu seu repertório de saberes e (re)significou a formação com as próprias crianças do berçário. Diz ela ao mostrar as fotografias: "tive respostas na minha vivência profissional. Viver junto com eles, eu me sentava e me rolava. Então eu coloquei isso, viver junto com eles. Aqui eu sentada brincando, cantando e a importância da socialização que tem para o bebê." (Violeta)

A professora Rosa traz, também, pela fotografia com uma das turmas de Educação Infantil que atuou, a significação das experimentações com as crianças, dizendo que: "o que sempre me chamou atenção que com a criança nada é para a "hora de", tudo pode ser vivido com eles (...) ser professor de crianças é estar em movimento com elas!".

Para Tomazzetti (2008, p. 86), 
a dimensão que os conhecimentos assumem na educação das crianças pequenas coloca-se uma relação extremamente vinculada aos processos gerais de constituição da criança: a expressão, o afeto, a sexualidade, a socialização, o brincar, a linguagem, o movimento, a fantasia, o imaginário, as suas cem linguagens. (...) Este conjunto de relações que poderia ser identificado como o objeto de estudo de uma «didática» da educação infantil, é que, num âmbito mais geral, estou preferindo denominar de Pedagogia da Educação Infantil ou até mesmo mais amplamente falando, de uma Pedagogia da Infância, que terá, pois, como objeto de preocupação a própria criança: seus processos de constituição como seres humanos em diferentes contextos sociais, sua cultura, suas capacidades intelectuais, criativas, estéticas, expressivas e emocionais.

A Pedagogia da Infância a que se refere a autora leva em consideração a formação de professores com novas posturas, incluindo a especificidade da Educação Infantil, de práticas e produções próprias das crianças, seus direitos respeitados e sua cultura reconhecida no seu tempo, como campo dos saberes das crianças.

Assim, foi se construindo a experiência formadora, de modo que os imaginários instituídos sobre a infância foram questionados, refletidos coletivamente, possibilitando um diálogo entre o passado, o presente e considerações pensadas para o futuro. Após o término da vivência, foi solicitado que a professora Rosa e a professora Violeta registrassem pela narrativa autobiográfica o que tinha de formativo para elas esse momento, as impressões, as implicações e significados construídos nesse dia.

Esta dimensão do método biográfico busca compreender os sentidos, as significações dadas aos fatos, às práticas, aos desejos, aos sonhos, aos conhecimentos, às crenças e aos valores compartilhados nessas vivências. De acordo com Josso (2004, p. 130),

(...) o trabalho biográfico faz parte do processo de formação; ele dá sentido, ajuda-nos a descobrir a origem daquilo que somos hoje. É uma experiência formadora que tem lugar na continuidade do questionamento sobre nós mesmos e de nossas relações com o meio.

Neste sentido, encontrei em Josso (2004) a possibilidade de conhecer, pela experiência formadora, os saberes docentes das professoras e o processo de (re) construção de suas experiências na graduação em Pedagogia e na atuação profissional tendo como "recordações-referências" individuais; histórias coletivas refletidas. Mais do que a rememoração de tempos e espaços de formação, a experiência formadora atuou na reflexão de si, como um processo de autoconhe- 
cimento que caracteriza subjetividades e identidades articuladas à pesquisa e à formação num contínuo aprender. Para Josso (2004, p. 235),

a experiência, as experiências de vida de um indivíduo são formadoras na medida em que, a priori ou a posteriori, é possível explicitar o que foi aprendido (iniciar, integrar, subordinar), em termos de capacidades, de saber-fazer, de saber pensar e de saber situar-se. O ponto de referência das aquisições experienciais redimensionam o lugar e a importância dos percursos educativos certificados na formação do aprendente, ao valorizarem um conjunto de atividades, de situações, de relações de acontecimentos como contextos formadores.

Foi revisitando os contextos formadores das professoras que foi possível trazer a infância para o lugar da pesquisa, da vida cotidiana de quem atua no âmbito da Educação Infantil. Portanto, a experiência foi formativa e ficou na narrativa escrita das professoras Violeta e Rosa o que significou experimentarem-se como autoras de seus saberes e significações imaginárias construídas a partir de seus trajetos formativos...

Estar aqui e registrar os pedaços da minha trajetória com as crianças dá um colorido especial ao que eu vivi com elas e como pensei continuar a contribuir com sua educação. Registrar e REVER o que fiz é como se movimentasse um pouco do que eu sou hoje, porque vejo que minha identificação com a criança foi produzida nessa vontade que ainda e sempre tenho de ser professora (Professora Rosa).

A experiência de hoje, reconstrução do conceito de infância, me fez pensar na minha identidade como professora de educação infantil, me fez desconstruir e construir alguns conceitos, fez "acordar" mais ainda a criança dentro de mim, me fez pensar em experimentar, descobrir, imaginar, mais e mais. (Professora Violeta).

Nesse sentido, salientamos a importância sobre a reflexão do vivido, dos sentidos e significados que tornam essa vivência em experiência formadora, pois as professoras pensaram sobre si, seus trajetos formativos e a implicação da formação em suas práticas cotidianas com as crianças, na infância e na educação. Para Josso (2004, p. 73),

no trabalho biográfico, esse conceito de experiência é utilizado para articular o processo de formação e o processo de conhecimento. Entremos, pois, naquilo que se torna em experiência. O primeiro momento de transformação de uma vivência em experiência inicia-se quando presta- 
mos atenção no que se passa em nós/e ou na situação na qual estamos implicados, pela nossa simples presença.

As narrativas biográficas representam a possibilidade de criar um imaginário instituinte em relação ao lugar da infância na formação docente. Podemos perceber isso, no momento em que elas (re)significam as representações e as identificações com a profissão e com as crianças. Segundo a Professora Rosa, esse foi o tempo em que puderam parar e pensar sobre os significados daquilo que elas vêm fazendo no cotidiano de sua profissão, das relações com o saber-fazer e saber-ser.

\section{NARRATNAS CONSTANTES}

Os estudos acerca da construção das infâncias em diferentes contextos, tempos e espaços institucionais ou não, têm ampliado o olhar e as discussões sobre o tema em diversos campos do conhecimento, incluindo a Pedagogia. Como vimos, a infância não é inerente às crianças e, segundo Sarmento (2005), é constituída por atores sociais concretos que em cada momento histórico, social, cultural, econômico de um tempo e espaço integram a categoria geracional.

Por isso, conhecer as infâncias e discuti-las na formação inicial é a possibilidade de perceber se o encontro entre criança e infância tem acontecido nos processos formativos. Esta questão nos parece pertinente na construção dos saberes docentes sobre a infância, pois é a partir destes encontros e desencontros que podemos perceber o quanto a infância é dinâmica e está em constante (des) construção, o que propicia um trabalho de reflexão crítica sobre os saberes acadêmicos e experienciais constituídos no processo formativo.

Neste sentido, encontramos na Pedagogia o lócus de reflexão e mediação dos saberes construídos sobre o lugar da infância em diferentes contextos e, com isso, a possibilidade de promover debates na formação de professores sobre os diferentes enfoques dado às infâncias. Corroboramos com Formosinho (2007, p. 31) quando diz que "a práxis é a casa da pedagogia".

A autora comenta que um modelo pedagógico pelos educadores de infância é um fator de sustentação da sua práxis e pode transformar-se em muro ou em janela. O muro quando a situação do "discursivismo", "teoricismo", causa uma valorização acentuada das teorias em detrimento ao que menciona ser a janela, uma estrutura conceitual e prática, um contexto de ação e "reflexão-sobre-a- 
-ação", "uma ponte entre as aprendizagens dos professores e as aprendizagens das crianças, entre os percursos de co-construção do conhecimento e da ética" (OLIVEIRA-FORMOSINHO, 2007, p.32).

Refletir o lugar da infância na formação de professores, no curso de Pedagogia, é estar atento às discussões sobre as demandas do ser professor na contemporaneidade e estabelecer um diálogo com as infâncias vividas e construídas no processo formativo dos docentes. Isso serve para repensarmos sobre essa pluralidade de significados e perceber a infância não como algo naturalizado, mas como direito que toda criança deveria ter de viver. Nesse sentido, tais reflexões, segundo Arroyo (2008, p. 121), "convidam a pedagogia a estar atenta à dinâmica da sociedade onde as imagens da infância se constroem e desconstroem".

Dessa forma, encontramos nas experiências formadoras e nas escutas dos saberes das professoras de Educação Infantil, egressas do curso de Pedagogia da UFSM, a possibilidade de vivenciar momentos de reflexão, (re)construção e (re) significação de experiências formativas sobre o lugar da infância na formação docente. Reconhecemos que este lugar não é estático, rígido e homogêneo, ele é como as infâncias, (re)construídas a cada (re)encontro com as crianças, com suas próprias infâncias e com as (re)significações que se proporcionam com seus saberes e de seus pares na profissão e fora dela.

Assim, as professoras Girassol, Rosa e Violeta e nós, como pesquisadoras, participamos como protagonistas da nossa própria história, dos saberes e das reflexões feitas por meio das experiências vividas, conflitos, incertezas e complexidades que envolveram escolhas, interações, aprendizagens e ações tanto individuais quanto coletivas. Nas palavras de Moita (1992, p. 115),

\footnotetext{
Ninguém se forma no vazio. Formar-se supõe troca, experiência, interacções sociais, aprendizagens, um sem fim de relações. Ter acesso ao modo como cada pessoa se forma é ter em conta a singularidade da sua história e sobretudo o modo singular como age, reage e interage com os seus contextos. Um percurso de vida é assim um percurso de formação, no sentido em que é um processo de formação.
}

Diante destas reflexões, encontro na formação de professores a possibilidade da formação/autoformação como construção si e (re)significação dos processos formativos que nos acompanham quando narramos nossa própria his- 
tória de vida, saberes e significações imaginárias, bem como a dimensão pessoal e profissional que nos constitui como professor.

\section{REFERÊNCIAS}

ALCÂNTARA, Angela Vieira de. Imagens e memórias do cotidiano: o que os olhos vêem? In: ALVES; Nilda; SGARBI, Paulo. (Orgs). Espaços e imagens na Escola. Rio de janeiro: DP\&A, 2001.

ARROYO, Miguel. A infância interroga a pedagogia. In: SARMENTO, Manuel; GOUVEA, Maria Cristina Soares de. Estudos da infância: saberes e práticas sócias. Petrópolis, RJ: Vozes, 2008.

CASTORIADIS, C. A Instituição Imaginária da Sociedade. $6^{\mathrm{a}}$ ed., Rio de Janeiro: Paz e Terra, 1982.

. As Encruzilhadas do Labirinto I: o domínio do homem. Rio de Janeiro: Paz e Terra, 1987.

DAL-FORNO, J. P. Imaginários e Saberes Docentes na Escoa Inclusiva: um estudo dos processos de formação e autoformação. 2005. 182f. Dissertação (Mestrado em Educação) - Universidade Federal de Santa Maria, Santa Maria, 2005.

FERREIRA; Nilda Tevês; EIZIRIK, Marisa Faermann. Imaginário Social e Educação: revendo a escola. Em Aberto, Brasília, ano 14, n.61, jan./mar. 1994.

HALBWACHS, M. A memória coletiva. São Paulo: Centauro, 2006.

JOSSO, Marie Christine. Experiências de Vida e Formação. São Paulo: Cortez, 2004.

As figuras de ligação nos relatos de formação: ligações formadoras, deformadoras e transformadoras. In: Revista Educação e Pesquisa, São Paulo, v.32, n.2, p. 373-383, maio/ago, 2006.

KUHLMANN JR, M. Infância e Educação Infantil: uma abordagem histórica.

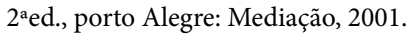

KUREK, D.L. Ensaio sobre um sentido da infância e possíveis relações com a docência. In: SEMINÁRIO DE PESQUISA EM EDUCAÇÃO DA REGIÃO SUL: PESQUISA EM EDUCAÇÃO E INSERÇÃO SOCIAL. 7., 2008, Itajaí. Anais... Itajaí, 2008. 1CD-ROM.

MARQUES, M. O. Professores Falantes de Si na Sala de Aula, na Escola e na Constituição da Pedagogia. In: OLIVEIRA, V.F. de. Imagens de Professor: signi- 


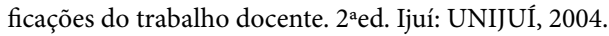

MOITA, M.C. Percursos de formação e Trans-formação. In: NÓVOA, A. Vidas de Professores. $2^{\text {a }}$ ed., Portugal: Porto Editora, 1992.

NÓVOA, António (Org). Vidas de professores. $2^{\mathrm{a}}$ ed., Portugal: Porto Editora, 1992.

OLIVEIRA-FORMOSINHO, J. Pedagogia(s) da infância: reconstruindo uma práxis de participação. In: OLIVEIRA-FORMOSINHO, J et al. Pedagogia(s) da infância: dialogando com o passado construindo o futuro. POA: Artmed, 2007.

OLIVEIRA, Valeska Fortes de. Imagens de professor: significações do trabalho docente. $2^{\text {a }}$ ed., Ijuí: Unijuí, 2004.

Narrativas e saberes docentes. Ijuí: Unijuí, 2006.

Formação docente: aprendizagens e significações imaginárias no espaço grupal. In: Revista Brasileira de Pesquisa sobre Formação Docente, Belo Horizonte, v. 02, n. 02, p. 68-82, jan./jul. 2010. Disponível em http://formacaodocente. autenticaeditora.com.br

OLIVEIRA, Valeska Fortes de; OLIVEIRA, Waléria Fortes de. Criança e infância: quando o encontro é marcado e não acontece. In:Vivências das infâncias: contextos e perspectivas. Cadernos temáticos/ OMEP. Santa Maria: Pallotti, 2005.

PIMENTA, Selma Garrido. Saberes pedagógicos e atividade docente. $4^{\mathrm{a}} \mathrm{ed}$. São Paulo: Cortez, 2005.

REDIN, M.M. Memórias de infância e de escola: experiência e criação. In: SEMINÁRIO DE PESQUISA EM EDUCAÇÃO DA REGIÃO SUL: PESQUISA EM EDUCAÇÃO E INSERÇÃO SOCIAL. 7, 2008, Itajaí. Anais... Itajaí, 2008. 1CD$-\mathrm{ROM}$

SARMENTO, Manuel Jacinto. Gerações e alteridade: interrogações a partir da Sociologia da Infância. In: Revista Educação e Sociedade, Campinas, v. 26, n. 91, p.361-378, 2005.

Sociologia da Infância: correntes e confluências. In: GOUVEA, Maria Cristina Soares de. Estudos da Infância: educação e práticas sociais. Petrópolis, RJ: Vozes, 2008.

SIMSON, Olga Rodrigues de Moraes Von (org.). Os desafios contemporâneos da história oral. Campinas, UNICAMP, 1997.

TARDIF, Maurice. Saberes Docentes e Formação Profissional. Petrópolis, RJ: Vozes, 2002. 
TOMAZZETTI, Cleonice Maria. Lugar de criança é na escola. Que escola? A educação da criança de zero a cinco anos. Revista Educação Cidadã. Ano 2008, vol.1, n.2. Santa Maria, 2008. Disponível em: www.santamaria.rs.gov/smed/revista/docs/200812_78.pdf. Acesso em: 14.06.2009.

THOMSON, Alistair. Recompondo a Memória. Questões sobre a relação entre a História Oral e as memórias. In: PERELMUITER, D. e ANTONACC1, M. A . (Orgs.) Ética e História Oral. São Paulo: PUC/SP. Revista do Programa de Estudos Pós-Graduados em História e do Departamento de História da PUC/SP, 1997.

\title{
NARRATIAS (AUTO)BIOGRÁFICAS ACERCA DE LAS INFANCIAS Y SUS LUGARES EN LA FORMACIÓN DOCENTE
}

\begin{abstract}
Resumen: Cuando nosotros proponemos investigar la vida del profesor, desarrollamos una escucha sensible de su historia, de sus saberes y los caminos construidos al largo de su formación docente. Fue por medio de eso que desarrollamos una propuesta de investigación-formación con tres profesoras de Educación Infantil, egresas del curso de Pedagogía, de la Universidade Federal de Santa Maria (UFSM)/RS, con la intención de estar cerca de sus imaginarios y narrativas (auto)biográficas acerca del lugar de la infancia en la formación docente. Nosotros utilizamos una investigación de abordaje cualitativa en el proceso de formación/ autoformación, basada en referenciales teórico-metodológicos que permiten la discusión acerca de la memoria, historia de la vida y narrativas (auto)biográficas construidas en dos "experiencias formadoras" llamadas "Baúl de memoria: recuerdos de formación" y "Álbum de infancias". Cada profesora trajo objetos personales almacenados en sus "baúls formativos" y narraron los sentidos y los significados en relación a la infancia en la formación inicial y en la experiencia profesional, a partir de sus "recuerdos-referencias". En la actualidad, los estudios acerca de la infancia caminan por areas distintas del conocimiento; conocer lo que los profesionales de la Pedagogía comprenden sobre la infancia es relevante para problematizar otras discusiones en ámbito de la educación. De esa manera, Christine Josso fue un de los aportes teóricos que permitió a nosotros una vivencia y repensar sobre las infancias vividas, proporcionadas, reconstruidas con los niños y en los debates en espacios académicos y de formación. Todo eso permitió una reflexión acerca del lugar que cada profesora da a la infancia en su formación docente.
\end{abstract}

Palabras-clave: Narrativas (auto)biográficas. Infancias. Formación docente. 


\title{
NARRATIVES (SELF)BIOGRAPHICAL ABOUT THE CHILDHOODS AND YOUR SPACES IN THE TEACHER FORMATION
}

\begin{abstract}
When we propose to research about the teacher's life, we develop a sensitive hear of his history, his knowledge and the ways built in the course of his teacher formation. Through this, we develop a proposal of research-formation with three teachers of Early Childhood Education, graduated in Pedagogy, of the Universidade Federal de Santa Maria (UFSM)/RS, with the intention approximate us of your imaginary and narratives (self)biographical about the place of the childhood in the teacher formation. We use a research of qualitative approach in the process of formation/self-formation, this is based in theoretical-methodological references that permit the discussion about memory, life history and self-biographical narratives built in two "formation experiences" entitled "Trunk of memory: memories of the formation" and "Childhood album". Each teacher brought personal objects saved in her "formatives trunks" and they narrate the meanings in relation to childhood in the beginning formation and in the professional experience, as of her "references-memories". Nowadays, the studies about the childhood transit for diferent fields of the knowledge; we emphasize that to know what the Pedagogy Professionals understand about the childhood is relevant to problematize others discussions in the education. Therefore, Christine Josso was one of the theoretical input that permit to experience and to rethink about the childhoods lived, proportionate, rebuilt with the children and in the debates in the academic and formation spaces. Thereby, we can to reflect about the place that these teachers are giving for the childhood in their teacher formation.
\end{abstract}

Key-words: Narratives (self)-biographical. Childhoods. Teacher formation. 